\title{
Lower Leg Length is Associated with Running Economy in High Level Caucasian Distance Runners
}

\author{
by \\ Rauno Laumets ${ }^{1}$, Karel Viigipuu ${ }^{1}$, Kerli Mooses ${ }^{1}$, Jarek Mäestu ${ }^{1}$, Priit Purge ${ }^{1}$, \\ Ando Pehme ${ }^{1}$, Priit Kaasik ${ }^{1}$, Martin Mooses ${ }^{1}$
}

\begin{abstract}
The aim of the present study was to investigate lower limb anthropometric and composition variables related to running economy (RE) and running performance in a homogeneous group of high level European distance runners. $R E$ at the speeds of 14, 16 and $18 \mathrm{~km} \cdot \mathrm{h}^{-1}\left(189 \pm 12 ; 188 \pm 11 ; 187 \pm 11 \mathrm{O}_{2} \mathrm{ml} \cdot \mathrm{kg}^{-1} \cdot \mathrm{km}^{-1}\right)$ and maximal oxygen uptake $\left(V O_{2 \max }\right)\left(67.3 \pm 2.9 \mathrm{ml} \cdot \mathrm{kg}^{-1} \cdot \mathrm{min}^{-1}\right)$ of 13 high level distance runners were determined on a motorised treadmill. Anthropometric variables and body composition were measured. The BMI was related to RE at the speed of $14\left(r^{2}=\right.$ 0.434; $p=0.014), 16\left(r^{2}=0.436 ; p=0.014\right)$ and $18 \mathrm{~km} \cdot \mathrm{h}^{-1}\left(r^{2}=0.389 ; p=0.023\right)$. Lower leg length was negatively related to RE at the speed of 16 and showed such a tendency at the speed of 14 and $18 \mathrm{~km} \cdot \mathrm{h}^{-1}$. VO2max indicated a moderate relationship with $R E$ at the speeds of 14,16 and $18 \mathrm{~km} \cdot \mathrm{h}^{-1}\left(r^{2}=0.372, p=0.030 ; r^{2}=0.350, p=0.033 ; r^{2}=\right.$ $0.376, p=0.026$, respectively) which was confirmed by subsequent partial correlation analysis. While lower leg length and the BMI presented a relationship with RE, none of the calculated body composition and anthropometric proportions were related to $R E$ or performance. The relationship between $R E$ and $V O_{2 m a x}$ would confirm the notion that $R E$ could be at least partly compensated by $\mathrm{VO}_{2 \max }$ to achieve high performance results.
\end{abstract}

Key words: running economy, maximal oxygen uptake, running performance, anthropometric characteristics, body composition, DEXA scan.

\section{Introduction}

In addition to different physiological parameters, several anthropometric and body composition variables are known to be associated with running performance in elite Caucasian middle- and long-distance runners (Arrese and Ostariz, 2006). For example, body height and mass (Maldonado et al., 2002), fat and fat free mass (Winter and Hamley, 1976), arm circumference (Knechtle et al., 2008), different lower limb skinfolds and circumferences (Arrese and Ostariz, 2006; Legaz and Eston, 2005; Tanaka and Matsuura, 1982) as well as the sum of three (Kong and de Heer, 2008) or six (Legaz and Eston, 2005) skinfolds have been related to distance running performance. However, there is equivocal data about how running economy (RE) is related to anthropometric and/or body composition variables. Runners with proportionally lower body mass concentrated in the extremities, particularly in the legs, would perform less work moving their body segments during running, if all other factors are unchanged (Myers and Steudel, 1985). Therefore, leg mass and the distribution of leg mass might be important characteristics in performance and RE of distance runners (Myers and Steudel, 1985). In contrast, no difference has been shown in RE between recreational athletes with similar body mass, but different body composition (Maciejczyk et al., 2015). Recent evidence (Mooses et al., 2015a) indicates that relatively longer legs are related to better performance, however, in a homogenous group of athletes RE has shown not to be related to performance (Foster et al., 1977; Mooses et al.,

1 - Faculty of Medicine, Institute of Sport Sciences and Physiotherapy, University of Tartu, Tartu, Estonia. 
2015a; Williams and Cavanagh, 1987). Although the body composition of runners has been examined extensively, often these studies have been conducted with relatively heterogeneous groups of runners (Arrese and Ostariz, 2006; Winter and Hamley, 1976). Furthermore, despite a number of analyses focused on different anthropometric variables in top level runners (Kong and de Heer, 2008; Lucia et al., 2006, 2008), there is a paucity of studies examining different leg proportions in relation with running performance and RE. With recent development in equipment, this has become easy and cost effective by using the Dual Energy X-ray Absorptiometry (DEXA) method.

It has been agreed that RE is not determined only by one variable, but it is rather a combination of factors to investigate especially at the highest performance level of distance running (Foster and Lucia, 2007; Mooses et al., 2015a; Saunders et al., 2004). Therefore, better understanding of the interaction between RE, $\mathrm{VO}_{2 \max }$, performance, body composition and anthropometrics of different level athletes as well as intensities is needed. To date, there is no consensus which factors are responsible for superior RE and how RE is related to $\mathrm{VO}_{2 \max }$. Thus, the aim of the present study was to investigate lower limb anthropometric and composition variables related to RE and running performance in a homogeneous group of high level European distance runners. It was hypothesized that relatively lighter and longer legs would be related to better RE at the speed of 14,16 and $18 \mathrm{~km}^{\cdot \mathrm{h}^{-1}}$. The findings of this study could help explain a complex interaction between anthropometric characteristics, body composition and RE in high level running performance.

\section{Material and Methods}

\section{Participants}

High level male European distance runners $(n=15)$ were initially recruited to the study, however, 2 of them were excluded after the treadmill test due to surpassing the second ventilatory threshold $\left(\mathrm{VT}_{2}\right)$ at the speed of 18 $\mathrm{km} \cdot \mathrm{h}^{-1}$. Therefore, the number of the subjects included into the final analysis was 13 (Table 1). The participation criteria were (i) regular training sessions during the last three years for a minimum of five times per week, (ii) average monthly mileage during the last year of at least $240 \mathrm{~km}$, (iii) inclusion in the top 10 on the National Athletics Association ranking list, and (iv) competing at international level. The best performance of the previous competition season (3-4 months before the study) of the athletes was established using the International Association of Athletics Federations (IAAF) Scoring Tables (Legaz and Eston, 2005; Lucia et al., 2008; Mooses et al., 2015a, b; Spiriev, 2011). These tables assign a definite score to each performance, enabling comparison between different events (Legaz and Eston, 2005; Mooses et al., 2015a). The participants of the present study were of a high performance level and included some of the athletes who had competed in indoor and/or outdoor European Championships.

\section{Procedures}

A cross-sectional study using a group of middle- and long-distance runners was carried out. During the first visit to the laboratory, athletes were familiarised with the treadmill and face masks that were used during the test on the second visit. On the second visit to the laboratory, the measurement of main anthropometric variables and the DEXA procedure preceded the treadmill test. Athletes were requested to abstain from high intensity training and/or competition for at least $24 \mathrm{~h}$ before testing and to maintain their usual dietary intake as well as to refrain from caffeine and alcohol. Study procedures and protocols were approved by the Research Ethics Committee of the University of Tartu, Estonia, and conformed to the Declaration of Helsinki. All testing procedures and related risks were described to the athletes before providing written informed consent to participate in the study.

\section{Measures}

Following the 10 min familiarisation with the treadmill (freely chosen speeds), participants performed an incremental running test on a motorized treadmill (Viasys LE 300 C 175/65, HP Cosmos Quasar Sports \& Medical GmbH Nussdorf-Traunstein, Germany) until voluntary exhaustion. Ten minutes of familiarisation were considered acceptable as previously it had been reported that for healthy adults who were inexperienced on a treadmill, even 6 minutes of treadmill running in one training session were sufficient before highly reliable lower limb angular kinetic variables could be measured 
(Lavcanska et al., 2005). Before commencement of the test, each athlete remained stationary on the treadmill for three minutes and cardio-respiratory data was collected. The initial running speed was set at $8 \mathrm{~km} \cdot \mathrm{h}^{-1}$ with a gradient of $1 \%$ (Jones and Doust, 1996; Lucia et al., 2005; Mooses et al., 2013a, b, 2015a, b) and was then increased by 2 $\mathrm{km} \cdot \mathrm{h}^{-1}$ every three minutes until $18 \mathrm{~km} \cdot \mathrm{h}^{-1}$. Following the $3 \mathrm{~min} 18 \mathrm{~km} \cdot \mathrm{h}^{-1}$ stage, the speed remained constant and elevation increased 1\% after every one minute until voluntary exhaustion (Mooses et al., 2015a, b). The heart rate (HR) and maximum running time on the treadmill $\left(t_{\max }\right)$ were recorded with a heart rate monitor Polar RS400 (Polar Electro Oy, Kempele, Finland). Expired gases were measured using MasterScreen CPX (Viasys Healthcare GmbH, Hoechberg, Germany), which was calibrated before each test according to instructions of the manufacturer. $\dot{\mathrm{V}} \mathrm{O}_{2 \max }$ was defined as highest average $\dot{\mathrm{VO}}_{2}$ during a $30 \mathrm{~s}$ period and a failure to further increase $\dot{\mathrm{VO}}_{2}$ despite an increase in the work rate (Wasserman et al., 2005). If participants did not reach the $\mathrm{VO}_{2}$ plateau, it was considered to be $\mathrm{VO}_{2 \text { peak }}$ rather than $\mathrm{VO}_{2 \text { max }}$. However, for an easier reading, we used the acronym $\mathrm{VO}_{2 \max }$ for all the participants (Billat et al., 2003). RE was calculated from the last two minute submaximal $\dot{\mathrm{VO}}_{2}$ of the 14, 16 and $18 \mathrm{~km} \cdot \mathrm{h}^{-1}$ stage. RE was expressed as oxygen cost $\left(\mathrm{O}_{2} \mathrm{ml} \cdot \mathrm{kg}^{-1} \cdot \mathrm{km}^{-1}\right)$ and was calculated as follows:

$$
R E=\frac{1000 \cdot \dot{V} O_{2}}{v},
$$

where $\dot{\mathrm{VO}}_{2}$ is steady-state oxygen uptake $(\mathrm{ml} \cdot \mathrm{kg}$ $\left.{ }^{1} \cdot \mathrm{min}^{-1}\right)$ and $\mathrm{v}$ is running velocity $\left(\mathrm{m} \cdot \mathrm{min}^{-1}\right)$ (Bragada et al., 2010). A steady state was defined as an increase of less than $100 \mathrm{ml} \mathrm{O}_{2}$ over the final two minutes of the respective running stage (Fletcher et al., 2009). VT2 (Table 2) was determined as the second rise in ventilation and as the intensity that accompanied the second rise in the $\mathrm{VE}-\mathrm{VO}_{2}$ relationship with a concurrent rise in the $\mathrm{VE}-\mathrm{VCO}_{2}$ relationship (Mooses et al., 2013a; Rabadan et al., 2011).

Body height (Altimetro, Gima Spa, Gessate, Italy) and body mass (Sartorius Combics 3, Sartorius AG, Goettingen, Germany) of the participants were measured to the nearest $0.5 \mathrm{~cm}$ and $0.05 \mathrm{~kg}$, respectively. In total, 4 girths (thigh, mid-thigh, calf, ankle) and 2 lengths (trochanterion height and tibiale laterale height) were measured using the Centurion Kit instrumentation (Rosscraft, Surrey, BC, Canada) according to protocols recommended by the International Society for Advancement of Kinanthropometry (Marfell-Jones et al., 2006). The series of anthropometric measurements were taken by a trained researcher who had previously shown test-retest reliability of $r>0.95$. The following calculations were made:

upper leg length = trochanterion (total leg length) tibiale laterale (lower leg length)

Body composition was measured by Dual Energy X-ray Absorptiometry (DXA) (Hologic QDR Discovery, Hologic Inc., Bedford, USA). The three compartments (lean, fat and bone) were measured with the participant in the supine position (Hetland et al., 1998). Total fat and lean mass were measured for the total body, upper leg (thigh) and lower leg (calf). In addition, the following anthropometric and body composition proportions were calculated:

1. leg mass to body mass: leg mass ( $\mathrm{kg}$ )/ body $\operatorname{mass}(\mathrm{kg}) * 100$

2. upper leg (thigh) mass to body mass: upper leg $(\mathrm{kg}) /$ body mass $(\mathrm{kg}) * 100$

3. lower leg (calf) mass to body mass: calf mass $(\mathrm{kg}) / \mathrm{body}$ mass $(\mathrm{kg}) * 100$

4. calf mass to thigh mass: calf mass $(\mathrm{kg}) /$ thigh $\operatorname{mass}(\mathrm{kg}) * 100$

5. leg length to body height: leg length $(\mathrm{m}) /$ total body height $(m) * 100$

6. upper leg (thigh) length to body height: upper leg $(m) /$ total body height $(m) * 100$

7. lower leg (calf) length to body height: lower leg $(m) /$ total body height $(m) * 100$

8. lower leg (calf) length to upper leg (thigh) length: lower leg $(m)$ /upper leg $(m) * 100$

\section{Statistical Analysis}

The normality of all variables was tested with the Shapiro-Wilk test. Pearson or Spearman, where necessary, correlation analyses were used to determine linear relationships between variables. To avoid spurious correlation between $\mathrm{RE}$ and $\mathrm{VO}_{2 \max }$, additionally a partial correlation was used to assess the relationship between absolute $\mathrm{VO}_{2 \max }$ and $\mathrm{RE}$ as oxygen cost $\left(\mathrm{L} \cdot \mathrm{min}^{-1}\right)$ (Shaw et al., 2015). Calculations were performed using IBM SPSS Statistics v.20 (SPSS Inc., Chicago, IL, USA). The level of significance was set at $p<$ 0.05 . 


\section{Results}

Runners were of a high performance level (Table 1) and with good RE (Table 3). RE and $\mathrm{VO}_{2 \max }$ values for individual athletes are shown in Figure 1.

$\mathrm{VO}_{2 \max }$ showed a moderate relationship with RE at the speeds of 14,16 and $18 \mathrm{~km} \cdot \mathrm{h}^{-1}\left(\mathrm{r}^{2}=\right.$ $0.372, p=0.030 ; \mathrm{r}^{2}=0.350, p=0.033 ; \mathrm{r}^{2}=0.376, p=$ 0.026 , respectively); however, the performance score was not related to RE at any of the speeds $(p>0.05)$. Partial correlation analysis controlling body mass confirmed positive relationships between submaximal $\mathrm{VO}_{2}$ at the speed of 14,16 and $18 \mathrm{~km} \cdot \mathrm{h}^{-1}$ and $\mathrm{VO}_{2 \max }\left(\mathrm{r}^{2}=0.426, p=0.021 ; \mathrm{r}^{2}=\right.$ $0.440, p=0.019 ; \mathrm{r}^{2}=0.350, p=0.042$, respectively). None of the measured and calculated proportions of different body segment masses (Table 4) were related to RE (Table 5), $\mathrm{VO}_{2 \max }$ or performance $(p>$ $0.05)$.

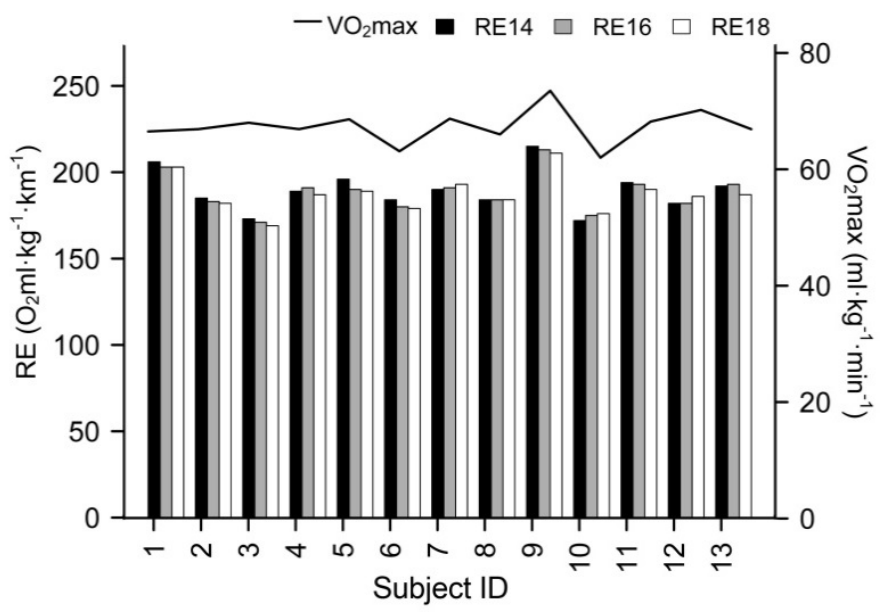

Figure 1

Running economy (RE) at the speed of 14,16 and $18 \mathrm{~km} \cdot \mathrm{h}^{-1}$ (black, dark-grey and light-grey bars, respectively) and maximal oxygen uptake $\left(\mathrm{VO}_{2 \max }\right)$ of the individual runners (solid line)

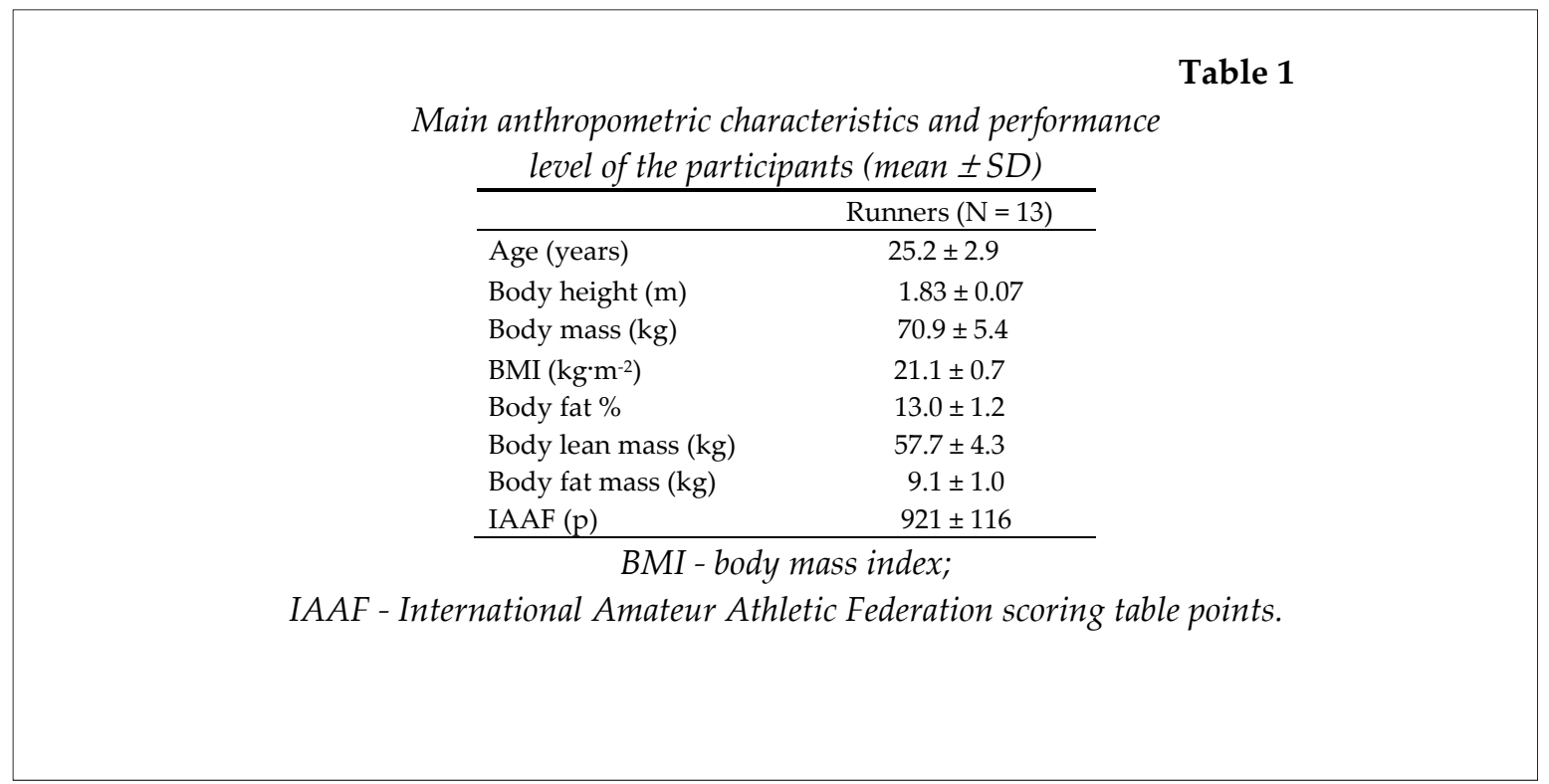


Table 2

Relative intensities from $\mathrm{VO}_{2 \max }$ and $\mathrm{HR}($ mean $\pm \mathrm{SD})$

\begin{tabular}{lcc}
\hline & $\% \mathrm{VO}_{2 \max }$ & $\% \mathrm{HR}_{\max }$ \\
\hline $14\left(\mathrm{~km} \cdot \mathrm{h}^{-1}\right)$ & $66 \pm 3$ & $81 \pm 4$ \\
$16\left(\mathrm{~km} \cdot \mathrm{h}^{-1}\right)$ & $75 \pm 4$ & $87 \pm 3$ \\
$18\left(\mathrm{~km} \cdot \mathrm{h}^{-1}\right)$ & $83 \pm 5$ & $91 \pm 3$ \\
$\mathrm{VT}_{2}$ & $92 \pm 3$ & $95 \pm 2$ \\
\hline
\end{tabular}

$\% \mathrm{VO}_{2 m a x}$ - percentage from maximal oxygen uptake;

$\% \mathrm{HR}_{\max }$ - percentage from the maximal heart rate;

$V T_{2}$ - second ventilatory threshold

Table 3

Variables of the incremental treadmill test (mean $\pm S D)$

\begin{tabular}{lc} 
& Runners $(\mathrm{N}=13)$ \\
\hline$t_{\max }(\mathrm{s})$ & $1618 \pm 108$ \\
$\mathrm{VO}_{2 \max }\left(\mathrm{ml} \cdot \mathrm{kg}^{-1} \cdot \mathrm{min}^{-1}\right)$ & $67.3 \pm 2.9$ \\
$\mathrm{RE} 14\left(\mathrm{O}_{2} \mathrm{ml} \cdot \mathrm{kg}^{-1} \cdot \mathrm{km}^{-1}\right)$ & $189 \pm 12$ \\
$\mathrm{RE} 16\left(\mathrm{O}_{2} \mathrm{ml} \cdot \mathrm{kg}^{-1} \cdot \mathrm{km}^{-1}\right)$ & $188 \pm 11$ \\
$\mathrm{RE} 18\left(\mathrm{O}_{2} \mathrm{ml} \cdot \mathrm{kg}^{-1} \cdot \mathrm{km}^{-1}\right)$ & $187 \pm 11$ \\
$\mathrm{VO}_{2} 14\left(\mathrm{ml} \cdot \mathrm{kg}^{-1} \cdot \mathrm{min}^{-1}\right)$ & $44.2 \pm 2.8$ \\
$\mathrm{VO}_{2} 16\left(\mathrm{ml} \cdot \mathrm{kg}^{-1} \cdot \mathrm{min}^{-1}\right)$ & $50.2 \pm 3.0$ \\
$\mathrm{VO}_{2} 18\left(\mathrm{ml} \cdot \mathrm{kg}^{-1} \cdot \mathrm{min}^{-1}\right)$ & $56.0 \pm 3.7$ \\
\hline
\end{tabular}

$t_{\max }$ - maximum time on the treadmill; $V O_{2 \max }$ - maximal oxygen uptake;

RE14, RE16 and RE18 - running economy at the speed of 14, 16 and $18 \mathrm{~km} \cdot \mathrm{h}^{-1}$;

$\mathrm{VO}_{2} 14, \mathrm{VO}_{2} 16, \mathrm{VO}_{2} 18$ - submaximal oxygen uptake at the speed of 14,16 and $18 \mathrm{~km} \cdot \mathrm{h}^{-1}$, respectively.

Table 4

Specific leg anthropometric and composition characteristics of the participants (mean $\pm S D$ )

\begin{tabular}{lc} 
& Runners (N =13) \\
\hline Circumferences (cm) & \\
\hline Thigh & $52.2 \pm 1.6$ \\
Mid-thigh & $49.2 \pm 1.6$ \\
Calf & $36.7 \pm 1.3$ \\
Ankle & $22.1 \pm 1.1$ \\
\hline & \\
Lengths (cm) & $91.3 \pm 4.4$ \\
\hline Total leg & $43.5 \pm 3.1$ \\
Upper leg & $47.8 \pm 2.8$ \\
Lower leg & \\
\hline Proportions of body lengths (\%) & $110.2 \pm 9.3$ \\
\hline Lower leg to upper leg length & $26.1 \pm 0.9$ \\
Lower leg to body height & $23.8 \pm 1.5$ \\
Upper leg to body height & $49.8 \pm 1.3$ \\
Total leg to body height & \\
\hline Proportions of body masses (\%) & $20.2 \pm 0.5$ \\
\hline Total leg to body mass & $14.4 \pm 0.5$ \\
Upper leg to body mass & $5.9 \pm 0.3$ \\
Lower leg to body mass & $41.1 \pm 3.0$ \\
Lower leg to upper leg mass & \\
\hline
\end{tabular}


Table 5

Correlation coefficients between running economy (RE)

and specific leg anthropometric and composition characteristics of the participants

\begin{tabular}{|c|c|c|c|}
\hline & $\begin{array}{c}\text { RE14 } \\
\left(\mathrm{O}_{2} \mathrm{ml} \cdot \mathrm{kg}^{-1} \cdot \mathrm{km}^{-1}\right)\end{array}$ & $\begin{array}{c}\text { RE16 } \\
\left(\mathrm{O}_{2} \mathrm{ml} \cdot \mathrm{kg}^{-1} \cdot \mathrm{km}^{-1}\right)\end{array}$ & $\begin{array}{c}\mathrm{RE} 18 \\
\left(\mathrm{O}_{2} \mathrm{ml} \cdot \mathrm{kg}^{-1} \cdot \mathrm{km}^{-1}\right)\end{array}$ \\
\hline \multicolumn{4}{|c|}{ Circumferences (cm) } \\
\hline Thigh & 0.004 & 0.004 & 0.016 \\
\hline Mid-thigh & 0.004 & 0.044 & 0.000 \\
\hline Calf & 0.001 & 0.002 & 0.041 \\
\hline Ankle & 0.027 & 0.078 & 0.112 \\
\hline \multicolumn{4}{|l|}{ Lengths (cm) } \\
\hline Total leg & 0.055 & 0.125 & 0.151 \\
\hline Upper leg & 0.015 & 0.000 & 0.004 \\
\hline Lower leg & 0.265 & $0.316^{*}$ & 0.303 \\
\hline \multicolumn{4}{|c|}{ Proportions of body lengths (\%) } \\
\hline Lower leg to upper leg & & 0.162 & 0.118 \\
\hline length & 0.225 & & \\
\hline Lower leg to body height & 0.127 & 0.129 & 0.149 \\
\hline Upper leg to body height & 0.140 & 0.084 & 0.055 \\
\hline Total leg to body height & 0.102 & 0.020 & 0.023 \\
\hline \multicolumn{4}{|c|}{ Proportions of body masses (\%) } \\
\hline Total leg to body mass & 0.006 & 0.002 & 0.012 \\
\hline Upper leg to body mass & 0.042 & 0.023 & 0.056 \\
\hline Lower leg to body mass & 0.038 & 0.081 & 0.075 \\
\hline Lower leg to upper leg & & 0.027 & 0.014 \\
\hline mass & 0.005 & & \\
\hline \multicolumn{4}{|c|}{$*-p<0.05$} \\
\hline
\end{tabular}

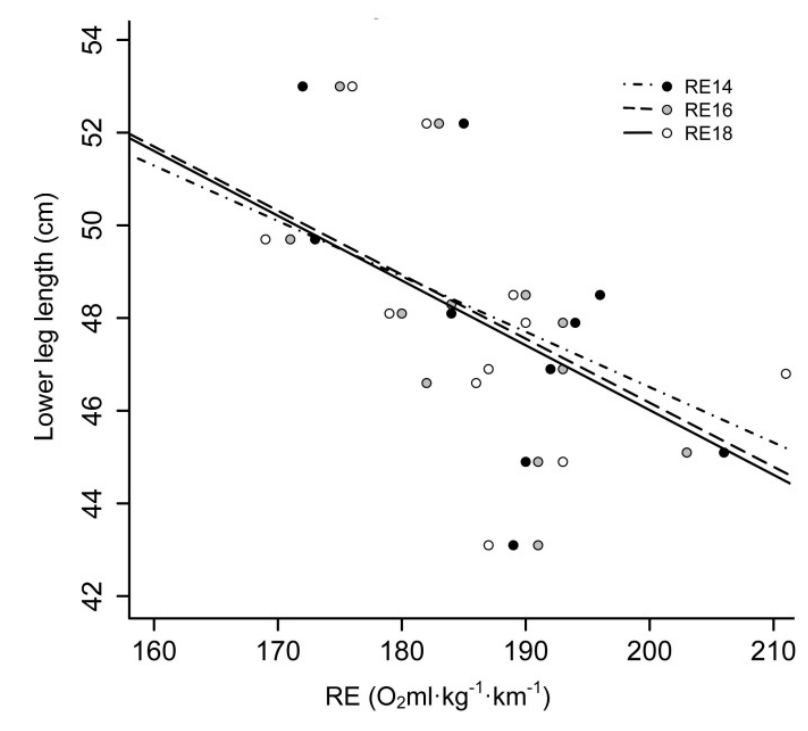

Figure 2

Relationship between lower leg length and running economy

(RE) at the speed of $14\left(r^{2}=0.265 ; p=0.072\right) ; 16\left(r^{2}=0.316 ; p=0.046\right)$ and $18\left(r^{2}=-0.303 ; p=0.051\right) \mathrm{km} \cdot \mathrm{h}^{-1}$ (black, grey and white circles, respectively) 
From anthropometric variables, the BMI was related to RE at the speeds of $14\left(\mathrm{r}^{2}=0.434 ; p=\right.$ $0.014), 16\left(\mathrm{r}^{2}=0.436 ; p=0.014\right)$ and $18 \mathrm{~km} \cdot \mathrm{h}^{-1}\left(\mathrm{r}^{2}=\right.$ $0.389 ; p=0.023)$. In addition, lower leg length was negatively correlated with RE at the speed of 16 $\mathrm{km}^{\cdot \mathrm{h}^{-1}}$ and showed a similar tendency at the speeds of 14 and $18 \mathrm{~km} \cdot \mathrm{h}^{-1}$ (Figure 2).

\section{Discussion}

The purpose of this study was to investigate anthropometric and body composition variables in relation with $R E$ at different submaximal speeds used in everyday training settings in a homogeneous group of high level European distance runners. Additionally, their performance, with particular emphasis on lower limb anthropometric and composition variables, was investigated. The important findings of this study were that in the homogeneous group of distance runners longer lower legs were associated with better RE at the speed of $16 \mathrm{~km} \cdot \mathrm{h}^{-1}$ and a similar trend was observed at the speeds of 14 and $18 \mathrm{~km} \cdot \mathrm{h}^{-1}$. Secondly RE was related to $\mathrm{VO}_{2 \max }$ at the range of measured speeds $(14,16$ and $18 \mathrm{~km} \cdot \mathrm{h}^{-1}$ ) and this indicates a complex and multifactorial interaction between $\mathrm{RE}, \mathrm{VO}_{2 \max }$ and performance.

Despite a number of studies describing different anthropometric variables of high level distance runners (Fudge et al., 2006; Marino et al., 2004; Prommer et al., 2010; Vernillo et al., 2013) there are only few (Lucia et al., 2008; Mooses et al., 2015a) that have paid attention to different anthropometric proportions, which in turn might be important characteristics in running performance and RE as a smaller amount of body mass in distal parts of extremities, specifically in the legs, would require less work in moving body segments during running (Myers and Steudel, 1985). Even though it is risky to compare different anthropometric (Vernillo et al., 2013) as well as body composition variables between the studies due to the variability in technique, equipment, as well as the site location, we found that lower limb circumferences and lengths in the present study were similar to those reported earlier for high level European distance runners (Lucia et al., 2006; Mooses et al., 2013a, b) and that circumferences were expectedly higher compared to elite East African runners (Kong and de Heer, 2008; Lucia et al., 2006; Mooses et al., 2015a;
Vernillo et al., 2013). A present finding that longer lower legs and a lower BMI were related to better $\mathrm{RE}$ at all the measured submaximal speeds $(14,16$ and $18 \mathrm{~km}^{-1}$ ) are somewhat in line with a previous study with high level East African distance runners, where relatively longer legs were shown to be advantageous for running performance (Mooses et al., 2015a). Previously, it has been indicated that RE is influenced by structural and physiological variables which in contrast differ to those related to running performance in high level runners (Mooses et al., 2015a; Sano et al., 2015). Despite RE being a good predictor of running performance, it may not necessarily explain the high performance level of elite athletes (Mooses et al., 2015a; Sano et al., 2015). Considering the examples of East African runners, despite the potential contribution of several biomechanical factors influencing RE, it has been argued that the superior RE is largely attributable to the low BMI and slim limbs with low masses that allow athletes to run with minimal energy used for swinging the limbs (Lucia et al., 2006; Saltin et al., 1995). It has been also stated that the precise mechanism explaining this relationship is not clear (Lucia et al., 2006). Oscillating long legs increases the energy cost of running in proportion to the limb mass moment of inertia and reduction in distal limb mass would produce substantial metabolic savings during running (Myers and Steudel, 1985). Likewise, shorter ground contact time has been related to better RE as there is less time for the braking force to decelerate forward motion of the body (Kong and de Heer, 2008; Mooses et al., 2015a; Nummela et al., 2007; Saltin et al., 1995; Santos-Concejero et al., 2013). The present finding with the homogeneous group of distance runners where no relationship between lower leg circumference as well as leg mass ratios and RE were found is in line with an earlier study (Lucia et al., 2006), where a relationship between calf circumference and submaximal $\mathrm{VO}_{2}$ was established when Spanish and Eritrean athletes were analysed as one group. However, such a relationship did not exist within the homogeneous group of Eritrean runners (Lucia et al., 2006). Alternatively, increasing stride length is more efficient than increasing frequency by devoting less energy to leg acceleration, longer legs favour longer stride length and therefore, allow better RE (Anderson, 
1996; Rahmani et al., 2004; Sleivert and Rowlands, 1996). It has to be noted that this explanation is valid up to $90 \%$ of individual maximum speed (Nummela et al., 2007), which was also the case in the present study. It can be argued that RE is influenced by lower limb anthropometric variables, however, equivocal data exist in describing the precise mechanism behind this phenomenon. It seems that anthropometric and body composition variables are of importance when determining RE among athletes with a broad range of the performance level, but not in a homogeneous group of high level athletes.

$\mathrm{VO}_{2 \max }$ values of the participants were similar compared to previous studies with high level European and East African runners (EsteveLanao et al., 2007; Maldonado et al., 2002; Mooses et al., 2015a; Tam et al., 2012; Weston et al., 2000) and RE was in the same range or better than previously reported in high level distance runners (Billat et al., 2003; Lucia et al., 2006; Maldonado et al., 2006; Tam et al., 2012; Weston et al., 2000). Our current finding that running performance was not related to RE is in line with earlier studies of European and East African runners (Foster et al., 1977; Mooses et al., 2015a; Williams and Cavanagh, 1987). This result confirms that a single variable or a small subset of variables cannot explain differences in RE, as it is rather influenced by combined effect of many variables (Mooses et al., 2015a; Williams and Cavanagh, 1987). More importantly there was an inverse relationship between $\mathrm{VO}_{2 \max }$ and $\mathrm{RE}$, indicating that athletes with superior economy had lower $\mathrm{VO}_{2 \max }$. It is supported by the literature, where better RE has been found to be associated with lower $\mathrm{VO}_{2 \max }$ in a heterogeneous group of recreational male and female runners (Pate et al., 1992) as well as an elite group of $10 \mathrm{~km}$ and marathon runners (Billat et al., 2001; Morgan and Daniels, 1994); this relationship was also confirmed by the recent data from East African (Mooses et al., 2015a) and European (Shaw et al., 2015) high level distance runners. A latter study where a small to moderate relationship was found between $\mathrm{RE}$ and $\mathrm{VO}_{2 \max }$, argued that with $>85 \%$ of the variance in these variables unexplained by this relationship, it was reaffirmed that $\mathrm{RE}$ and $\mathrm{VO}_{2 \max }$ were primarily determined independently (Shaw et al., 2015).

In contrast, it has been discussed that higher $\mathrm{VO}_{2 \max }$ could compensate lower $\mathrm{RE}$ and indeed cycling efficiency (Lucia et al., 2002; Mooses et al., 2015a; Morgan and Daniels, 1994). However, this hypothesis has been questioned as spurious correlation because of small sample sizes as well as the validity of the statistical techniques due to consideration of both variables in relation to body mass (Pate et al., 1992; Shaw et al., 2015). A recent study (Shaw et al., 2015) suggested that spurious correlations between $\mathrm{RE}$ and $\mathrm{VO}_{2 \max }$ could be avoided by removing the influence of body mass on partial correlations, which in turn would enable to examine the true relationship between these variables. It has to be noted that in the present study removing the influence of body mass strengthened the relationships between RE $\left(\mathrm{O}_{2} \mathrm{ml} \cdot \mathrm{kg}^{-1} \mathrm{~km}^{-1}\right)$ and relative $\mathrm{VO}_{2 \max }$ as well as absolute submaximal $\mathrm{VO}_{2}\left(\mathrm{~L} \cdot \mathrm{min}^{-1}\right)$ and $\mathrm{VO}_{2 \max }$ $\left(\mathrm{L} \cdot \mathrm{min}^{-1}\right)$ at all the measured speeds. Discussion in this area is to be continued (Atkinson et al., 2003; Lucia et al., 2002; Mooses et al., 2016; Morgan and Pate, 2004; Santos-Concejero and Tucker, 2016) especially considering that understanding the relationships between $\mathrm{RE}$ and $\mathrm{VO}_{2 \max }$ is necessary to tailor individualised training plans that lead to maximal performance in distance running.

The limitations of the present study should also be discussed. We had a relatively small sample size and we did not measure the Achilles tendon moment arm, that has been given a lot of attention during recent years (Mooses et al., 2015a; Raichlen et al., 2011; Sano et al., 2015; Scholz et al., 2008) and could contribute to RE. On the other hand, the strengths of this study were using the precise DEXA method for body composition analysis and the evaluation of RE at three submaximal speeds commonly used in everyday training settings.

In conclusion, while lower leg length and the BMI indicated a relationship with RE, none of the calculated body composition and anthropometric proportions were related to RE or performance in the homogenous group of competitive level European distance runners. The importance of lower leg length to RE will be most likely mediated through a more efficient running stride. Dissociation between RE and performance and, in contrast, the association between RE and $\mathrm{VO}_{2 \max }$ would suggest that RE could be at least partially compensated by $\mathrm{VO}_{2 \max }$ to achieve high performance as proposed earlier (Mooses et al., 2015a). The identification of the specific 
anthropometric variables that could characterize $\mathrm{RE}$ of distance runners is important and could be used for talent identification and performance prediction.

\section{Acknowledgements}

The authors wish to specially thank the subjects for their participation and cooperation.

\section{References}

Anderson T. Biomechanics and running economy. Sports Med, 1996; 22: 76-89

Arrese AL, Ostariz ES. Skinfold thicknesses associated with distance running performance in highly trained runners. J Sports Sci, 2006; 24: 69-76

Atkinson G, Davison R, Passfield L, Nevill AM. Could the correlation between maximal oxygen uptake and "economy" be spurious? Med Sci Sports Exerc, 2003; 35: 1242-1243

Billat V, Lepretre PM, Heugas AM, Laurence MH, Salim D, Koralsztein JP. Training and bioenergetic characteristics in elite male and female Kenyan runners. Med Sci Sports Exerc, 2003; 35: 297-304

Billat VL, Demarle A, Slawinski J, Paiva M, Koralsztein JP. Physical and training characteristics of top-class marathon runners. Med Sci Sports Exerc, 2001: 33; 2089-2097

Bragada JA, Santos PJ, Maia JA, Colaco PJ, Lopes VP, Barbosa TM. Longitudinal study in 3,000 m male runners: relationship between performance and selected physiological parameters. J Sports Sci Med, 2010; 9: 439-444

Esteve-Lanao J, Foster C, Seiler S, Lucia A. Impact of training intensity distribution on performance in endurance athletes. J Strength Cond Res, 2007; 21: 943-949

Fletcher JR, Esau SP, Macintosh BR. Economy of running: Beyond the measurement of oxygen uptake. J Appl Physiol, 2009; 107: 1918-1922

Foster C, Daniels J, Yarbrough RA. Physiologicaland training correlates of marathon running performance. Aust J Sports Med, 1977; 9: 58-62

Foster C, Lucia A. Running economy: the forgotten factor in elite performance. Sports Med, 2007; 37: 316-319

Fudge BW, Klaas RW, Kiplamai FK, Onywera VO, Boit MK, Kayser B, Pitsiladis YP. Evidence of negative energy balance using doubly labelled water in elite Kenyan endurance runners prior to competition. Br J Nutr, 2006; 95: 59-66

Hetland ML, Haarbo J, Christiansen C. Regional body composition determined by dual-energy x-ray absorptiometry. Relation to training, sex hormones, and serum lipids in male long-distance runners. Scand J Med Sci Sports, 1998; 8: 102-108

Jones AM, Doust JH. A $1 \%$ treadmill grade most accurately reflects the energetic cost of outdoor running. J Sports Sci, 1996; 14: 321-327

Knechtle B, Knechtle P, Schulze I, Kohler G. Upper arm circumference is associated with race performance in ultra-endurance runners. Br J Sports Med, 2008; 42: 295-299

Kong PW, de Heer H. Anthropometric, gait and strength characteristics of Kenya distance runners. J Sports Sci Med, 2008; 7: 499-504

Lavcanska V, Taylor NF, Schache AG. Familiarization to treadmill running in young unimpaired adults. Hum Mov Sci, 2005; 24: 544-57

Legaz A, Eston R. Changes in performance, skinfold thicknesses, and fat patterning after three years of intense athletic conditioning in high level runners. Br J Sports Med, 2005; 39: 851-856

Lucia A, Esteve-Lanao J, Olivan J, Gomez-Gallego F, San Juan AF, Santiago C, Perez M, Chamorro-Vina C, Foster C. Physiological characteristics of the best eritrean runners-exceptional running economy. Appl 
Physiol Nutr Metab, 2006; 31: 530-540

Lucia A, Hoyos J, Perez A, Santalla MPA, Chi-Charro JL. Inverse relationship between $\mathrm{VO}_{2}$ max and economy/efficiency in world-class cyclists. Med Sci Sports Exerc, 2002; 34: 2079-2084

Lucia A, Olivan J, Bravo J, Gonzalez-Freire M, Foster C. The key to top-level endurance running performance: A unique example. Br J Sports Med, 2008; 42: 172-174

Maciejczyk M, Wiecek M, Szymura J, Szygula Z, Cempla J. Physiological response during running in athletes with similar body mass but different body composition. Science \& Sports, 2015; 30: 204-212

Maldonado S, Mujika I, Padilla S. Influence of body mass and height on the energy cost of running in highly trained middle- and long-distance runners. Int J Sports Med, 2002; 23: 268-272

Marfell-Jones M, Olds T, Stewart A, Carter L. International standards for anthropometric assessment (2006 ed.). Adelaide: International Society for the Advancement of Kinanthropometry (ISAK); 2006

Marino FE, Lambert MI, Noakes TD. Superior performance of African runners in warm humid but not in cool environmental conditions. J Appl Physiol, 2004; 96: 124-130

Mooses M, Jürimäe J, Mäestu J, Mooses K, Purge P, Jürimäe T. Running economy and body composition between competitive and recreational level distance runners. Acta Physiol Hung, 2013a; 100: 340-346

Mooses M, Jürimäe J, Mäestu J, Purge P, Mooses K, Jürimäe T. Anthropometric and physiological determinants of running performance in middle- and long-distance runners. Kinesiology, 2013b; 45: $154-162$

Mooses M, Mooses K, Haile DW, Durussel J, Kaasik P, Pitsiladis YP. Letter to the editor. J Sports Sci, 2016; 34: 99-100

Mooses M, Mooses K, Haile DW, Durussel J, Kaasik P, Pitsiladis YP. Dissociation between running economy and running performance in elite Kenyan distance runners. J Sports Sci, 2015a; 33: 136-144

Mooses M, Tippi B, Mooses K, Durussel J, Mäestu J. Better economy in field running than on the treadmill: evidence from high-level distance runners. Biol Sport, 2015b; 32: 155-159

Morgan DW, Daniels JT. Relationship between $\mathrm{VO}_{2 \max }$ and the aerobic demand of running in elite distance runners. Int J Sports Med, 1994; 15: 426-429

Morgan DW, Pate R. Could the correlation between maximal oxygen uptake and "economy" be spurious? Med Sci Sports Exerc, 2004; 36: 345

Myers M, Steudel K. Effect of limb mass and its distribution on the energetic cost of running. J Exp Biol, 1985; 116: 363-373

Nummela A, Keränen T, Mikkelsson LO. Factors related to top running speed and economy. Int J Sports Med, 2007; 28: 655-661

Pate RR, Macera CA, Bailey SP, Bartoli WP, Powell KE. Physiological, anthropometric, and training correlates of running economy. Med Sci Sports Exerc, 1992; 24: 1128-1133

Prommer N, Thoma S, Quecke L, Gutekunst T, Völzke C, Wachsmuth N, Niess AM, Schmidt W. Total hemoglobin mass and blood volume of elite Kenyan runners. Med Sci Sports Exerc, 2010; 42: 791-797

Rabadan M, Diaz V, Calderon FJ, Benito PJ, Peinado AB, Maffulli N. Physiological determinants of speciality of elite middle- and long-distance runners. J Sports Sci, 2011; 29: 975-982

Rahmani A, Locatelli E, Lacour, JR. Differences in morphology and force/velocity relationship between Senegalese and Italian sprinters. Eur J Appl Physiol, 2004; 91: 399-405

Raichlen DA, Hunter A, Lieberman DE. Calcaneus length determinesrunning economy: Implications for endurance running performance in modernhumans and Neandertals. J Hum Evol, 2011; 60: 299-308

Saltin B, Larsen H, Terrados N, Bangsbo J, Bak T, Kim CK, Svedenhag J, Rolf CJ. Aerobic exercise capacity at sea level and at altitude in Kenyan boys, junior and senior runners compared with Scandinavian runners. Scand J Med Sci Sports, 1995; 5: 209-221 
Sano K, Nicol C, Akiyama M, Kunimasa Y, Oda T, Ito A, Locatelli E, Komi P, Ishikawa M. Can measures of muscle-tendon interaction improve our inderstanding of the superiority of Kenyan endurance runners? Eur J Appl Phyisol, 2015; 115: 849-859

Santos-Concejero J, Granados C, Irazusta J, Bidaurrazaga-Letona I, Zabala-Lili J, Tam N, Gil SM. Differences in ground contact time explain the less efficient running economy in north African runners. Biol Sport, 2013; 30: 181-187

Santos-Concejero J, Tucker R. Comment on Dissociation between running economy and running performance in elite Kenyan distance runners. J Sports Sci, 2016; 34: 96-98

Saunders PU, Pyne DB, Telford RD, Hawley A. Factors affecting running economy in trained distance runners. Sports Med, 2004; 34: 465-485

Scholz MN, Boobert MF, van Soest AJ, Clark JR, van Heerden J. Running biomechanics: shorter heels, better economy. J Exp Biol, 2008; 211: 3266-3271

Shaw AJ, Ingham SA, Atkinson G, Folland JP. The correlation between running economy and maximal oxygen uptake: cross-sectional and longitudinal relationships in highly trained distance runners. PLoS ONE, 2015; 10: e0123101. doi:10.1371/journal.pone.0123101

Sleivert GG, Rowlands DS. Physical and physiological factors associated with success in the triathlon. Sports Med, 1996; 22: 8-18

Spiriev B. IAAF Scoring Tables of Athletics. Revised ed. Monaco: Multiprint; 2011

Tam E, Rossi H, Moia C, Berardelli C, Rosa G, Capelli C, Ferretti G. Energetics of running in top-level marathon runners from Kenya. Eur J Appl Physiol, 2012; 112: 3797-3806

Tanaka K, Matsuura Y. A multivariate analysis of the role of certain anthropometric and physiological attributes in distance running. Ann Hum Biol, 1982; 9: 473-482

Vernillo G, Schena F, Berardelli C, Rosa G, Galvani C, Maggioni M, Agnello L, La Torre A. Anthropometric characteristics of top-class Kenyan marathon runners. J Sports Med Phys Fitness, 2013; 53: 403-408

Wasserman K, Hansen JE, Sue DY, Stringer WE, Whipp BJ. Measurements during integrative cardiopulmonary exercise testing. In: Wasserman K, Hansen E, Sue Y, Stringer E, Whipp J, editors. Principles of exercise testing and interpretation. Including pathophysiology and clinical applications. 4th ed. Philadelphia: Lippincott Williams \& Wilkins, 100-105; 2005

Weston AR, Mbambo Z, Myburgh HK. Running economy of African and Caucasian distance runners. Med Sci Sports Exerc, 2000; 32: 1130-1143

Williams KR, Cavanagh PR. Relationship between distance running mechanics, running economy,and performance. J Appl Physiol, 1987; 63: 1236-1245

Winter EM, Hamley EJ. Submaximal oxygen uptake related to fat free mass and lean leg volume in trained runners. Br J Sports Med, 1976; 10: 223-225

\section{Corresponding author:}

\section{Martin Mooses;}

Faculty of Medicine, Institute of Sport Sciences and Physiotherapy,

University of Tartu, Tartu, Estonia

Jakobi 5, Tartu 51014 Estonia;

Phone: +372 53463066;

E-mail: Martin.Mooses@ut.ee 